\title{
Risk factors in acute diabetic foot syndrome: analysis of 75 consecutive patients referred to a tertiary center in Modena, Italy
}

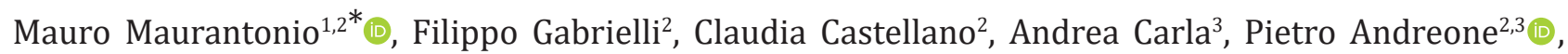 \\ Luca Roncucci ${ }^{2,3}$ (1) \\ ${ }^{1}$ Department of Internal Medicine, General, Emergency and Post-Acute, Diabetic Foot Unit, Ospedale Civile di Baggiovara, \\ Azienda Ospedaliero Universitaria di Modena, 41126 Modena, Italy \\ ${ }^{2}$ Division of Metabolic Internal Medicine, Ospedale Civile di Baggiovara, Azienda Ospedaliero Universitaria di Modena, 41126 \\ Modena, Italy \\ ${ }^{3}$ Department of Surgical and Medical Sciences, University of Modena and Reggio Emilia, 41124 Modena, Italy
}

*Correspondence: Mauro Maurantonio, Division of Metabolic Internal Medicine, Ospedale Civile Baggiovara, Azienda Ospedaliero Universitaria di Modena, via P. Giardini 1355, 41126 Modena, Italy. maurantonio.mauro@aou.mo.it

Academic Editor: Lindsay A. Farrer, Boston University School of Medicine, USA

Received: November 4, 2020 Accepted: January 6, 2021 Published: February 28, 2021

Cite this article: Maurantonio M, Gabrielli F, Castellano C, Carla A, Andreone P, Roncucci L. Risk factors in acute diabetic foot syndrome: analysis of 75 consecutive patients referred to a tertiary center in Modena, Italy. Explor Med. 2021;2:98-109. https:// doi.org/10.37349/emed.2021.00035

\begin{abstract}
Aim: Diabetic foot syndrome (DFS) is a complication of diabetes in which the presence of infections, ulceration and/or destruction of deep tissue associated with neuropathy, peripheral atherosclerosis and comorbidity affect the prognosis, the need for limb amputation and quality of life. Purpose of the present study is to report the features of patients with acute DFS admitted to our Diabetic Foot Unit tertiary Center in 2019.

Methods: In all patients admitted, the approach was performed through a multidisciplinary team (Diabetic Foot Care Team) and described in a specific diagnostic-therapeutic-assistance program. Criteria of inclusion were presence of sepsis and/or suspected osteomyelitis and/or critical limb ischemia. Clinical features and interventions performed were registered. Primary endpoints were mortality and amputation (major, minor). Secondary endpoints were length of hospitalization, type of revascularization and duration of antibiotic therapy.

Results: Among 75 consecutive patients (mean age 70.9 years) enrolled, prevalence of acute DFS was higher among men (M/F 3:1). Poor glycemic control [mean hemoglobin A1c (HbA1c) $67.9 \pm 22.3 \mathrm{mmol} / \mathrm{mol}$ ], long duration of diabetes (mean $19 \pm 16.3$ years), high low-density lipoprotein-cholesterol (mean $89.5 \pm 45.1 \mathrm{mg}$ / $\mathrm{dL}$ ) and obesity (mean Body Mass Index $30.2 \pm 7.6 \mathrm{~kg} / \mathrm{m}^{2}$ ) were common. Diabetes-related complications as peripheral arterial disease (PAD) (76\%), ischemic heart disease (48\%), retinopathy (40.5\%), hepatic steatosis (50\%), heart failure (17.8\%) were present. During hospitalization, 21 subjects (28.4\%) underwent lower limb amputations (overall rate of major amputation 4\%), and $41.3 \%$ underwent percutaneous angioplasty. Long period of hospitalization (18.4 \pm 7.9 days) and prolonged antibiotic therapy (23.9 \pm 15.9 days) were observed. Major amputation was associated with C-reactive protein $>6.5 \mathrm{mg} / \mathrm{dL}(P=0.03)$, osteomyelitis $(P$ $=0.001)$, prior insulin therapy $(P=0.015)$.

\footnotetext{
(C) The Author(s) 2021. This is an Open Access article licensed under a Creative Commons Attribution 4.0 International License (https://creativecommons.org/licenses/by/4.0/), which permits unrestricted use, sharing, adaptation, distribution and reproduction in any medium or format, for any purpose, even commercially, as long as you give appropriate credit to the original author(s) and the source, provide a link to the Creative Commons license, and indicate if changes were made.
} 
Conclusions: Male sex, co-morbidity, PAD, systemic inflammation and poor glycemic control are major features of acute hospitalized DFS. An approach through a multidisciplinary team is recommended in order to treat vascular and extra-vascular complications aimed at reducing mortality and at improving quality of life.

\section{Keywords}

Co-morbidity, diabetic foot syndrome, diabetic ulcer, limb amputation, nonalcoholic fatty liver disease, multidisciplinary team, mortality, sex differences

\section{Introduction}

The diabetic foot syndrome (DFS) defines a cluster of diabetes-related morbid conditions including sensory neuropathy, immunopathy, arthropathy and peripheral arterial disease (PAD), with a global prevalence of 6.3\% and in which unrecognized tissue injury can lead to foot ulceration, infection and risk of limb amputation. Diabetic foot prevalence is higher in men (4.5\%) than in women (3.5\%) and in type-2 diabetes (T2D) (6.4\%) than in type-1 diabetes (T1D) (5.5\%) [1].

In diabetics with foot ulcer, neuropathy, ischemia, infection and the presence of multi-morbidity affect the prognosis, the need for limb amputation and the quality of life [2]. Further risk factors are age, prolonged duration of diabetes, smoking, poor glycemic control, peripheral neuropathy and/or PAD, anatomical abnormalities, retinopathy, past history of foot ulcer or distal amputation [3-6]. Conversely, the role of sex, a major modifier of disease and nonalcoholic fatty liver disease (NAFLD), a relatively novel cardiovascular risk factor in T2D, remain incompletely characterized [7-11].

The treatment of diabetic foot is the most expensive complication of diabetes $[12,13]$ and DFS exposes to high morbidity and mortality [14-15]. In DFS, the management of complexity through a global bio-psychosocial approach able to plan personalized assistance and an integrated multidisciplinary team significantly reduce mortality and the risk of infections and major amputation, improving outcomes and quality of life [1, 16-19]. In 2019, in the University Hospital of Modena a multidisciplinary multi-professional team (Diabetic Foot Care Team) was set up, led by an Internist, and including physicians from other medical disciplines, integrated by technical nursing skills. The Diabetic Foot Care Team is described in a specific diagnostictherapeutic assistance program (DTAP) issued and approved by the local health care system, and it is in charge to serve as a referral center systematically taking care of all patients presenting with both T2D and signs/symptoms related to lower limbs in the Province of Modena, Northern Italy.

In the present study, we addressed some relevant research questions relating to clinical presentation, co-morbidity and other factors such sex differences, prevalence rates of NAFLD and other features associated with DFS and their association with limb amputation.

\section{Methods}

This is a retrospective observational study performed using a registration system on a cohort of 75 consecutive patients admitted to the Diabetic Foot Unit of Modena since January 1 through December 31, 2019, namely the first year of activity of our center. The Diabetic Foot Care Team composed by specialists in Internal Medicine (team leader), Endocrinology and Diabetology, Vascular Surgery, Orthopedics, Dermatology, Radiology, Microbiology, Infectious Disease, Clinical Nutrition, Physiatry and Clinical Psychology, integrated by technical nursing skills is described in detail in a specific DTAP.

Criteria of inclusion were: presence of signs/symptoms of sepsis, suspicion of osteomyelitis and/or critical limb ischemia. Criteria of exclusion: individuals who were unable or refuse to provide consent to participate in the study and subjects under 18 years. Demographic and anthropometric data such as age, sex, weight, height, body-mass-index (BMI) were registered. Historical data relating to the presence of comorbidities, previous revascularization, current therapy were recorded at admission, along with all diagnostictherapeutic interventions performed during hospitalization. The average length of hospitalization and clinical outcomes were also recorded. "PAD" was defined as obstructive atherosclerotic vascular disease with clinical 
symptoms, signs or abnormalities on non-invasive vascular assessment, resulting in disturbed or impaired circulation in one or more extremities; "osteomyelitis" was defined as infection of the bone, with radiological signs of involvement of the bone marrow; "major amputation" was defined as any resection proximal to the ankle; "minor amputation" was defined as any resection through or distal to the ankle, according to the International Working Group on Diabetic Foot (IWGDF) criteria [2]. "Ischemic heart disease" was defined as history of non-fatal myocardial infarction or coronary revascularization; "chronic kidney disease (CKD)" was defined as presence of progressive renal function decline; "retinopathy" was defined as presence/history of vitreous hemorrhage, blindness or requirement for intra-vitreal agent or photocoagulation. Despite the limitations, especially in obese [20,21], liver steatosis was defined through ultrasound-based criteria as mild, moderate, severe. Primary endpoints of the study were mortality, major and minor amputations. Secondary endpoints were length of hospitalization, type of revascularization, transfer to intensive care and duration of antibiotic therapy.

Statistical analyses were carried out with the SPSS 21 software (IBM, Armonk, NY, USA) for Windows® operating system. All continuous numerical variables were reported as mean \pm SD; nominal variables were reported as absolute frequency and \% of the total. Mean differences were compared using Student's $t$-test, frequency differences with $\chi^{2}$ test. Differences between means, and associations between variables were considered statistically significant when the probability of chance differences and associations were below $5 \%(P<0.05)$. Variables statistically significant in univariate analyses were used in multivariate models in order to find the ones independently related to osteomyelitis and amputation. The present study was approved by the local Ethics Committee.

\section{Results}

We evaluated 75 patients ( $73.3 \%$ men and $26.7 \%$ women), mean age 70.9 years (range $47-93$ ), with a mean time of hospitalization of $18.4 \pm 7.9$ days (Table 1 ). In our series, the mean duration of T2D was $19 \pm 16.3$ years, and the mean BMI was $30.2 \pm 7.6 \mathrm{~kg} / \mathrm{m}^{2}$. At admission, poorly compensated T2D was reported in most cases: median glycated haemoglobin (HbA1c) was $67.9 \pm 22.3 \mathrm{mmol} / \mathrm{mol}$ whereas blood glucose was $196.9 \pm$ $105.9 \mathrm{mg} / \mathrm{dL}$. In half of the subjects hepatic steatosis was absent (Table 2). Most patients revealed micro and macrovascular complications of diabetes: PAD (76\% of cases), ischemic heart disease (50\%), CKD (48\%), and retinopathy $(40.5 \%)$.

Table 1. Main demographic, diseases and therapeutic characteristics, and diagnostic and surgical interventions in the study population with DFS

\begin{tabular}{ll}
\hline Characteristics & Mean value $\mathbf{S}$ SD \\
\hline Sex Males $(\%)$ & 73.3 \\
Age (years) & $70.9 \pm 10.35$ \\
Age of onset of T2D (years) & $49.2 \pm 15.5$ \\
Duration of diabetes (years) & $19.2 \pm 16.3$ \\
BMI $\left(\mathrm{Kg} / \mathrm{m}^{2}\right)$ & $30.2 \pm 7.6$ \\
Systolic Blood Pressure $(\mathrm{mmHg})$ & $143.7 \pm 20.5$ \\
Diastolic Blood Pressure $(\mathrm{mmHg})$ & $75.5 \pm 10.9$ \\
Heart Rate (bpm) & $80.4 \pm 14.4$ \\
Glasgow Come Scale $(0-15)$ & $14.9 \pm 0.3$ \\
Pain scale (NRS 0-10) & $2.6 \pm 3.4$ \\
Body Temperature $\left({ }^{\circ} \mathrm{C}\right)$ & $36.5 \pm 0.7$ \\
\hline Co-morbidity at admission & Frequency (\%) \\
\hline Heart failure & 17.8 \\
Soft tissue inflammation & 82.7 \\
Osteomyelitis & 56 \\
PAD & 76 \\
Retinopathy & 40.5 \\
\hline
\end{tabular}


Table 1. Main demographic, diseases and therapeutic characteristics, and diagnostic and surgical interventions in the study population with DFS (continued)

\begin{tabular}{|c|c|}
\hline Co-morbidity at admission & Frequency (\%) \\
\hline CKD (no. of patients) & 48 \\
\hline Stage IIla (eGFR 59-45 mL/min) & 20 \\
\hline Stage IIIb (eGFR 44-30 mL/min) & 12 \\
\hline Stage IV (eGFR 29-15 mL/min) & 12 \\
\hline Stage $V($ eGFR $<15 \mathrm{~mL} / \mathrm{min})$ & 4 \\
\hline Ischemic Heart Disease & 50 \\
\hline Atrial Fibrillation & 14.7 \\
\hline Previous Stroke & 13.3 \\
\hline Active cancer & 5.4 \\
\hline Dementia & 4 \\
\hline Hepatic Steatosis & 16 \\
\hline COPD & 6.7 \\
\hline Smokers & 12.3 \\
\hline Therapy at admission & Frequency (\%) \\
\hline Anti-hypertensive & 74.7 \\
\hline Oral antidiabetics & 56.8 \\
\hline Insulin & 54.1 \\
\hline Antiplatelet agents & 64.4 \\
\hline Statins & 54.1 \\
\hline Primary Endpoints & Frequency (\%) \\
\hline \multirow[t]{3}{*}{ Lower limb amputation (total 21 patients) } & $28.4 \%$ \\
\hline & Major: $4.1 \%$ \\
\hline & Minor/Curative: $24.3 \%$ \\
\hline Mortality in Diabetic Foot Unit (no patient) & $0 \%$ \\
\hline Secondary Endpoints & Mean value \pm SD \\
\hline In-hospital duration of antibiotic therapy (days) & $18 \pm 9.8$ \\
\hline Total duration of antibiotic therapy (days) & $23.9 \pm 15.9$ \\
\hline Time of hospital stay (days) & $18.4 \pm 7.9$ \\
\hline Others & Frequency (\%) \\
\hline Percutaneous angioplasty & $41.3 \%$ \\
\hline Transfer to Intensive Care Unit (total 4 patients) & $5.3 \%$ \\
\hline
\end{tabular}

Table 2. Biochemical assays of the 75 patients admitted in the Diabetic Foot Unit

\begin{tabular}{ll}
\hline Characteristics & Mean value \pm standard deviation \\
\hline HbA1c $(\mathrm{mmol} / \mathrm{mol})$ & $67.9 \pm 22.3$ \\
Blood Glucose $(\mathrm{mg} / \mathrm{dL})$ & $196.9 \pm 105.9$ \\
White blood cells $\left(10^{9} / \mathrm{L}\right)$ & $10.8 \pm 4.9$ \\
Neutrophils white-blood cells $\left(10^{9} / \mathrm{L}\right)$ & $9.3 \pm 8.9$ \\
$\mathrm{Hb}(\mathrm{g} / \mathrm{dL})$ & $11.5 \pm 1.8$ \\
Sideremia $(\mu \mathrm{g} / \mathrm{dL})$ & $38.1 \pm 22.1$ \\
Transferrin $(\mathrm{mg} / \mathrm{dL})$ & $189.7 \pm 52.1$ \\
Transferrin saturation $(\%)$ & $15.2 \pm 10.0$ \\
Ferritin $(\mathrm{ng} / \mathrm{mL})$ & $301.6 \pm 479.9$ \\
CRP $(\mathrm{mg} / \mathrm{dL})$ & $9.4 \pm 8.6$ \\
Procalcitonin $(\mathrm{ng} / \mathrm{mL})$ & $2.7 \pm 8.4$ \\
Blood Urea $(\mathrm{mg} / \mathrm{dL})$ & $60.3 \pm 40.6$ \\
Creatinin $(\mathrm{mg} / \mathrm{dL})$ & $1.4 \pm 0.9$ \\
Total cholesterol $(\mathrm{mg} / \mathrm{dL})$ & $144.4 \pm 55.7$ \\
HDL $(\mathrm{mg} / \mathrm{dL})$ & $32.4 \pm 10.7$ \\
LDL $(\mathrm{mg} / \mathrm{dL})$ & $89.5 \pm 45.1$ \\
\hline
\end{tabular}


Table 2. Biochemical assays of the 75 patients admitted in the Diabetic Foot Unit (continued)

\begin{tabular}{ll}
\hline Characteristics & Mean value \pm standard deviation \\
\hline TG $(\mathrm{mg} / \mathrm{dL})$ & $146.6 \pm 56.2$ \\
Uric acid (mg/dL) & $5.6 \pm 2.2$ \\
Total Bilirubinemia $(\mathrm{mg} / \mathrm{dL})$ & $0.7 \pm 0.4$ \\
Direct Bilirubinemia $(\mathrm{mg} / \mathrm{dL})$ & $0.2 \pm 0.1$ \\
AST $(\mathrm{U} / \mathrm{L})$ & $21.0 \pm 15.3$ \\
ALT $(\mathrm{U} / \mathrm{L})$ & $20.3 \pm 24.2$ \\
GGT $(\mathrm{U} / \mathrm{L})$ & $63.9 \pm 74.9$ \\
ALK-P $(\mathrm{U} / \mathrm{L})$ & $113.6 \pm 56.7$ \\
B12 vitamin $(\mathrm{ng} / \mathrm{L})$ & $345.9 \pm 228.7$ \\
D-vitamin $(\mathrm{ng} / \mathrm{mL})$ & $16.4 \pm 17.5$ \\
Folic acid $(\mathrm{ng} / \mathrm{mL})$ & $9.1 \pm 9.7$ \\
BNP $(\mathrm{ng} / \mathrm{L})$ & $728.9 \pm 1083.7$ \\
Albumin $(\mathrm{g} / \mathrm{dL})$ & $3.1 \pm 0.5$ \\
\hline
\end{tabular}

Co-morbidities: chronic atrial fibrillation (14.7\%), previous stroke (13.3\%), cancer (5.4\%), smoking habit (12.3\%), chronic obstructive pulmonary disease (COPD) (6.7\%) were observed. Thirteen patients (17.8\%) had heart failure.

Drug treatment: drug therapy at home included angiotensin converting enzyme (ACE)-inhibitors or sartans $(27 \%$ and $11.3 \%$ of patients respectively), beta-blockers $(47.3 \%)$, other vasodilators (5.5\%). Antiplatelet agents, i.e., acetylsalicylic acid (74.5\%) or the association clopidogrel + acetylsalicylic acid (14.9\%) were reported in $64.4 \%$ of patients. Oral antidiabetics were used by $56.8 \%$ of patients, whereas insulin alone by $54.1 \%$. Statins were taken by $54.1 \%$ of patients.

Physical, laboratory and imaging findings: at admission, mean systolic blood pressure was $143.7 \pm 20.5$ $\mathrm{mmHg}(1 \mathrm{mmHg}=0.133 \mathrm{kPa})$ and mean diastolic blood pressure was $75 \pm 10.9 \mathrm{mmHg}$; mean heart rate was $80.4 \pm 14.4$ beats per minute (bpm) and average body temperature was $36.5 \pm 0.7^{\circ} \mathrm{C}$. Hospitalized patients showed an increase in indices of systemic inflammation: neutrophilic leukocytosis (white blood cells $10.8 \pm$ $\left.4.9 \times 10^{9} / \mathrm{L}, \mathrm{N}=9.3 \pm 8.9 \times 10^{9} / \mathrm{L}\right)$, procalcitonin $(2.7 \pm 8.4 \mathrm{ng} / \mathrm{mL})$ and C-reactive protein (CRP) $(9.4 \pm 8.6 \mathrm{mg} /$ $\mathrm{dL}$ ). In the $82 \%$ of patients clinical signs of skin and soft tissues inflammation was identified; in 42 patients (56\%) osteomyelitis was diagnosed through radiological imaging (X-ray, computerized tomography or magnetic resonance). In 57 patients ( $76 \%$ of total) PAD was present; in $73.6 \%$ of them (42 subjects) vascular obstruction was revealed through angiography while in $26.3 \%$ of them (15 subjects) the diagnosis of PAD was based on anamnestic findings. In $82.7 \%$ of patients extensive microbiological evaluation was carried out; $10.7 \%$ of patients underwent bone biopsy, while debridement or surgical evacuation of phlegmon was performed in $33.8 \%$ and $23 \%$ respectively (Table 3). In $8.2 \%$ of patients blood cultures were positive, and positivity of blood cultures was significantly associated with osteomyelitis $(P=0.026)$. In multivariate analysis, only insulin therapy appeared to be an independent factor for osteomyelitis, but not for total amputation.

Table 3. Amputation, osteomyelitis and risk factors in 75 patients with DFS enrolled in the study

\begin{tabular}{lllll}
\hline Total Amputations & Risk Factor & Amputation NO & Amputation YES & $\boldsymbol{P}$ value \\
\cline { 2 - 5 } (major and minor) & CRP $>$ 65mg/L & 6 & 15 & 0.03 \\
& Osteomyelitis & 3 & 18 & 0.001 \\
& Insulin therapy & 5 & 16 & 0.015 \\
& Duration of diabetes $(\geq 20$ years) & 9 & 13 & 0.055 \\
& HbA1c $>55 \mathrm{mmol} / \mathrm{mol}$ & 4 & 17 & 0.165 \\
& Previous revascularization & 6 & 15 & 0.089 \\
\hline Osteomyelitis & Risk Factor & Osteomyelitis NO & Osteomyelitis YES & $\boldsymbol{P}$ value \\
\cline { 2 - 5 } & CRP $>$ 65 mg/L & 13 & 29 & 0.001 \\
& Total Amputations & 24 & 18 & 0.001 \\
& White blood cells $>12 \times 109 / \mathrm{L}$ & 24 & 18 & 0.003 \\
\hline
\end{tabular}


Treatment: during hospitalization, antibiotic therapy was administered to $98.7 \%$ of patients, in $77.3 \%$ via injective route; the mean duration of antibiotic therapy was $23.9 \pm 11.59$ days. $41.3 \%$ of patients were submitted to percutaneous angioplasty; the most affected vessels were the posterior tibial artery (47.6\%) and the anterior tibial artery (45.2\%). In the whole cohort of patients admitted to the Diabetic Foot Unit, the Multidisciplinary Team, coordinated by an Internal Medicine doctor, involved more than 20 specialists, mainly Vascular Surgeons (94.7\%) and Infectious Disease specialists. During hospitalization, 21 patients (28.4\%) were submitted to lower limb amputations: only in 3 of them a major amputation was performed while 18 patients $(24.3 \%)$ underwent curative minor amputation for either osteomyelitis or gangrene. Four patients were transferred to an Intensive Care Unit, while no death was observed in the Unit.

\section{Discussion}

This study was conducted on a cohort of 75 consecutive patients admitted to our Diabetic Foot Unit, as part of a DTAP for the management of T2D with DFS. The four main findings of the study were the followings: DFS appeared to be a sexually dimorphic disease; patients have deranged cardio-metabolic parameters; markers of inflammation seemed to be associated with amputation; DFS had a high rate of co-morbidities that reflect severity of diabetes.

\section{Is DFS a sexually dimorphic disease?}

Male sex seemed to be associated with DFS complications, with a male/female ratio of 3:1 $(73.3 \%$ vs. 26.7\% respectively). Similar results were observed in a recent meta-analysis [22]. Other observational studies have confirmed the male prevalence of complicated diabetic foot disease, in which the female sex, however, would be burdened by worse outcomes [23, 24]. Poor foot self-care, characterized by not regularly checking feet, poor hygiene and unhealthy habits were more frequent in a cross-sectional study conducted in a sample of 1,515 patients with T2D aged 40 year-old or older [25]. In previous observational studies, women with PAD, when compared to men, seem to have a more pronounced pro-inflammatory profile [26, 27]. However, our preliminary study does not enable us to draw any firm conclusions as to the potential association of sex and outcomes, because this was not a population-based study.

\section{Deranged cardiometabolic control and insulin therapy}

Most patients hospitalized in the acute phase presented with poor metabolic control and had raised indices of systemic inflammation. In our cases, patients hospitalized with DFS had a long disease duration (19 years) and poor glycemic control. Low-density lipoprotein (LDL)-cholesterol was high, too, and $76 \%$ of patients had PAD, conditioning an increased cardiovascular risk. Statins improve the lipid profile and exerted pleiotropic effects including plaque stabilization, regression of atheroma and anti-inflammatory effects able to minimizing cardiovascular risk in high risk subjects; however, the role of lipid-lowering drugs in PAD patients requires further studies [28]. Cardiovascular prevention guidelines recommend reaching the LDL-cholesterol target $<70 \mathrm{mg} / \mathrm{dL}$ in high-risk subjects and a target of $<55 \mathrm{mg} / \mathrm{dL}$ in very high-risk subjects with cardiovascular disease and/or multiple cardiovascular risk factors [29, 30]. Patients with diabetic foot ulcer (DFU), especially if PAD or other relevant co-pathologies such as CKD are present, should be considered at very high risk [31, 32]. In our cohort, only $54.1 \%$ of patients used statins and this fact conflicts with recommendations of international guidelines. In our series of patients, a similar deviation from the blood pressure target was observed with median values of $143.7 \mathrm{mmHg}$, i.e. above those recommended target values (systolic blood pressure $<140 \mathrm{mmHg}$ and diastolic blood pressure $<90 \mathrm{mmHg}$ ) that prevent cardiovascular events and microvascular complications [33-37]. The American Diabetes Association suggests lower targets if atherosclerotic cardiovascular disease (ASCVD) is present [35]. The finding that hospitalized patients with T2D and acute DFS do not reach the therapeutic targets in primary and secondary prevention suggests that it is necessary to implement therapeutic models and strategies to reduce the incidence of cardiovascular complications and to improve outcomes in patients with DFS. It is known that DFU is a condition of infection and ulceration sometimes accompanied by destruction of deep tissue (Figure 1). Our results therefore, confirm the presence of a sensitive neuropathy in which poor glycemic control plays a major role [38, 39]. In our study there seems 
to be an association between the use of home insulin therapy and total amputations $(P=0.015)$, seemingly in contrast with some evidence in recent literature supporting either a neutral or a protective effect of insulin on the cardiovascular outcomes [40-42]. In T2D, insulin treatment is usually started after secondary failure of oral hypoglycemic therapy. However, there is a long duration of illness before this occurs; thus, it is the duration of illness, rather than the use of insulin, that could be the true risk factor associated with amputation. In our study, the association of amputation with median duration of T2D is intriguing, though it did not reach statistical significance $(P=0.055)$, probably owing to the limited patient population.

(A)

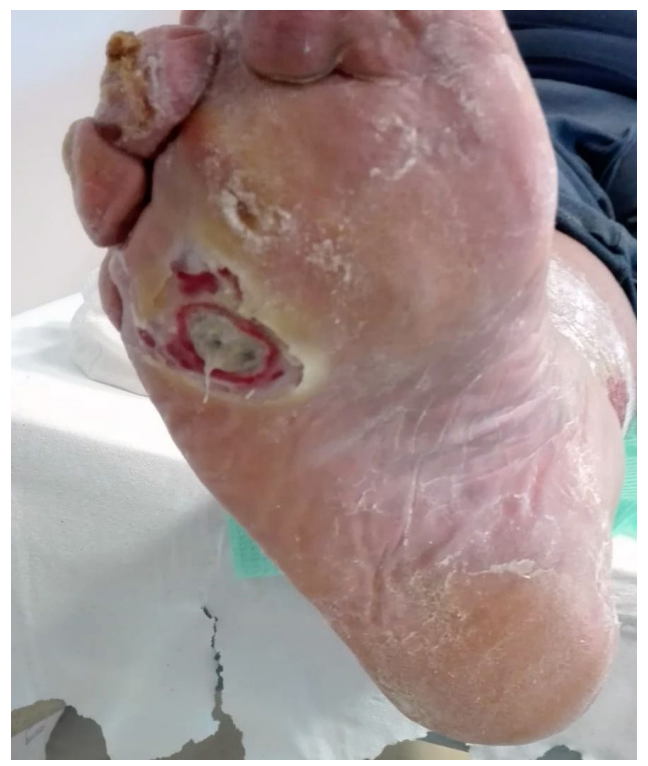

(B)

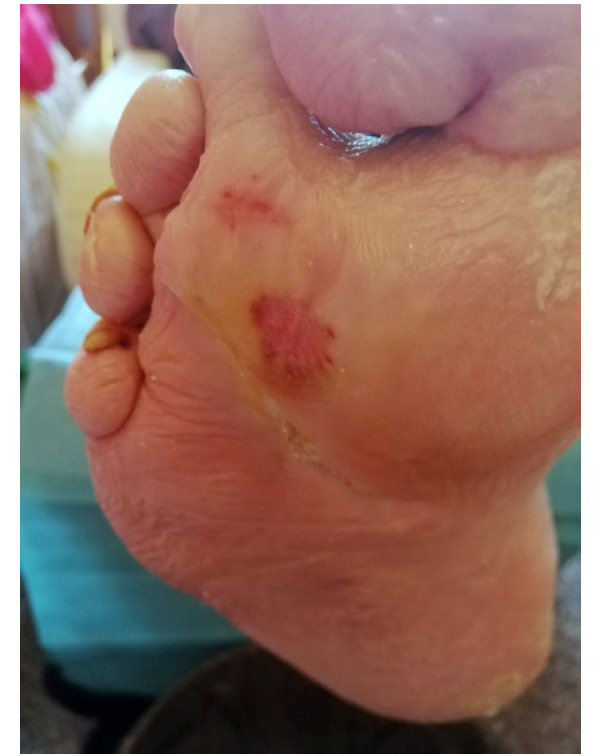

Figure 1. Foot ulcer before $(A)$ and after $(B)$ the intervention of multidisciplinary team

\section{Systemic and local inflammation}

The systemic inflammatory state plays a key role in development of vascular complications and in predisposing to hospitalization [43]. In a randomized study carried out on about 18,000 seemingly healthy subjects with low LDL-cholesterol levels but with high C Reactive Protein (CRP), it was found that the administration of statin significantly reduced the incidence of cardiovascular events [44-46]. In our patients, the intensity of painful symptoms linked to ischemia and/or local peripheral inflammation, assessed by the numerical rating scale (NRS), was $2.6 \pm 3.4$; only in $2-3 \%$ of cases it was necessary to implement the analgesic therapy by paintherapy specialists.

Although the team's criteria for amputation were clinical and radiological, in our study a CRP $>6.5 \mathrm{mg} /$ $\mathrm{dL}$ was found to be associated with total amputations $(P=0.03)$ and with presence of osteomyelitis $(P=$ 0.001). The same association was also found between osteomyelitis and total amputations $(P=0.001)$ such as discussed below. Based on these results, CRP may be considered a sensitive test to identify patients with the worst prognosis.

\section{Co-morbidities}

In our patients with acute DFS, PAD is confirmed to be a highly prevalent condition (76\% of cases); furthermore, retinopathy (40.5\%), CKD (48\%), ischemic heart disease $(50 \%)$ were also found. Half of patients had hepatic steatosis. Patients with NAFLD are at an increased risk for cardiovascular disease [47] and NAFLD is a well-defined risk factor for the future development of T2D and Metabolic Syndrome [48]. Patients with T2D will worsen the course of NAFLD and, conversely, patients with NAFLD were at higher risk for cardiovascular complications of T2D [49]. In a cross-sectional study on 2,646 T2D patients, patients with NAFLD had significantly higher prevalence of PAD compared with those without NAFLD; this association was much stronger among women than among men [50]. Further studies are needed to screen for hepatic steatosis with/without fibrosis even with non-invasive tests [51].

In consideration of the available evidence, comorbidities reflect severity of diabetes, unhealthy lifestyle habits and failure to achieve cardiovascular prevention targets $[6,30]$. 


\section{Outcomes}

Our study shows a statistically significant association between amputations and CRP $>6.5 \mathrm{mg} / \mathrm{dL}(P=0.03)$, osteomyelitis $(P=0.01)$ and prior therapy with insulin $(P=0.015)$ (Table 3$)$. With regard to the duration of diabetes ( $>20$ years), the relationship is interesting although not statistically significant $(P=0.055)$; the same trend was observed for the previous revascularization data $(P=0.089)$. In our study, HbA1c levels seem not associated with amputation $(P=0.165)$. In our sample, osteomyelitis seems strongly associated with: $\mathrm{CRP}>6.5 \mathrm{mg} / \mathrm{dL}(P=0.001)$, risk of amputation $(P=0.001)$, leukocytosis $>12 \times 10^{9} / \mathrm{L}(P=0.003)$ and prior therapy with insulin $(P=0.003)$. High levels of high-sensitivity CRP, a marker of inflammation, are associated to poor cardiovascular prognosis in obesity and in metabolic syndrome [52,53]. Simple steatosis is no more considered a benign condition and NAFLD is associated to cardio-renal complications [14, 54]. Although evidence suggests an association between NAFLD and T2D, in this study the relationship between BMI, glycemic status and presence of hepatic fibrosis with risk of amputation is unclear.

\section{Limitations and strengths}

Size of the sample, retrospective design, and lack of a control group admitted to general hospital wards are points of weakness of the present study, which have prevented more in-depth statistical analyses. Our study is homogeneous with respect to the final patient allocation, which allowed the standardization of diagnoses [according to the International Classification of Diseases, Ninth Edition-Clinical Modification (ICD9-CM) system] and treatment schedules.

Despite these limitations, in this study, conducted in a cohort of 75 consecutive patients admitted in the Diabetic Foot Unit of the Third Level Center of the Modena University Hospital, a prevalence of male sex, poor glycemic control, systemic inflammation, prolonged hospitalization time, presence of PAD and need for invasive interventions in acute presentation of DFS were observed, and confirmed the complexity of DFS. Statins were found to be used by only half of patients, and this fact reinforces the need to tackle patients to adhere to the recommended therapies. Additional studies are needed to evaluate the impact of co-morbidities on the risk of major amputation. Moreover, adequate screening and prevention programs should be further developed among patients with long-standing T2D and particularly among those with ASCVD aimed at achieving the recommended metabolic targets, establishing "scores" allowing the identification of patients at higher risk for complications and amputation, and thus reducing the incidence of acute DFS. Future studies should evaluate, in a larger sample size, the most relevant risk factors linked to DFS risk, in order to reach a more targeted prevention, an earlier diagnosis, and a faster therapy of patients with such a harmful syndrome.

\section{Abbreviations}

BMI: body-mass-index

CKD: chronic kidney disease

CRP: C-reactive protein

DFS: diabetic foot syndrome

DTAP: diagnostic-therapeutic-assistance program

HbA1c: hemoglobin A1c

NAFLD: nonalcoholic fatty liver disease

PAD: peripheral arterial disease

\section{Declarations}

\section{Author contributions}

MM and CC conceived and designed this study. MM, AC, PA and FG designed the statistical analysis and analyzed the data. MM, FG, CC, AC and LR interpreted the results. MM wrote the first draft of manuscript. MM, FG, CC and LR contributed to the writing of the manuscript. All authors have read and confirmed the data in the manuscript and they can take the responsibility for the integrity of the data and the accuracy of the data analysis, read and approved the submitted version. 


\section{Conflicts of interest}

The authors declare that they have no conflict of interest.

\section{Ethical approval}

The study was approved by the local Ethics Committee (reference number 855/2019).

\section{Consent to participate}

Informed consent to participate in the study was obtained from all participants.

\section{Consent of publication}

Not applicable.

\section{Availability of data and materials}

The raw data supporting the conclusions of this manuscript will be made available by the authors to any qualified researcher. The datasets generated and/or analyzed during the current study are not publicly available as they are held by AOU Modena Health Organization as an integral part of their statutory activity. Any request for access should be directly submitted to Principal Investigator/Author.

\section{Funding}

Not applicable.

\section{Copyright}

(C) The Author(s) 2021.

\section{References}

1. Zhang P, Lu J, Jing Y, Tang S, Zhu D, Bi Y. Global epidemiology of diabetic foot ulceration: a systematic review and meta-analysis. Ann Med. 2017;49:106-16.

2. Navarro-Flores E, Cauli O. Quality of life in individuals with diabetic foot syndrome. Endocr Metab Immune Disord Drug Targets. 2020;20:1365-72.

3. Schaper NC, van Netten JJ, Apelqvist J, Bus SA, Hinchliffe RJ, Lipsky BA, et al. Practical guidelines on the prevention and management of diabetic foot disease (IWGDF 2019 update). Diabetes Metab Res Rev. 2020; 36 Suppl 1:e3266.

4. Hingorani A, LaMuraglia GM, Henke P, Meissner MH, Loretz L, Zinszer KM, et al. The management of diabetic foot: a clinical practice guidelines by the Society for Vascular Surgery in 88 collaboration with the American Podiatric Medical Association and the Society for Vascular Medicine. J Vasc Surg. 2016;63:3S-21S.

5. Prompers L, Schaper N, Apelqvist J, Edmonds M, Jude E, Mauricio D, et al Prediction of outcome in individuals with diabetic foot ulcers: focus on the differences between individuals with and without peripheral arterial disease. The EURODIALE Study. Diabetologia. 2008;51:747-55.

6. Prompers L, Huijberts M, Apelqvist J, Jude E, Piaggesi A, Bakker K, et al. High prevalence of ischaemia, infection and serious comorbidity in patients with diabetic foot disease in Europe. Baseline results from the Eurodiale study. Diabetologia. 2007;50:18-25.

7. Mauvais-Jarvis F, Merz NB, Barnes PJ, Brinton RD, Carrero J, DeMeo DL, et al. Sex and gender: modifiers of health, disease and medicine. Lancet. 2020;396:565-82.

8. Targher G, Lonardo A, Byrne CD. Nonalcoholic fatty liver disease and chronic vascular complications of diabetes mellitus. Nat Rev Endocrinol. 2017;14:99-114.

9. Shatnawi NJ, Al-Zoubi NA, Hawamdeh HM, Khader YS, Garaibeh K, Heis HA. Predictors of major lower limb amputation in type 2 diabetic patients referred for hospital care with diabetic foot syndrome. Diabetes Metab Syndr Obes. 2018;11:313-9. 
10. Bohn B, Grunerbel A, Altmeier M, Giesche C, Pfeifer M, Wagner C, et al. Diabetic foot syndrome in patients with diabetes. A multicenter German/Austrian DPV analysis on 33,870 patients. Diabetes Metab Res Rev. 2018;34:e3020.

11. Seghieri G, Policardo L, Gualdani E, Anichini R, Francesconi P. Gender difference in the risk of cardiovascular events or mortality of patients with diabetic foot syndrome. Acta Diabetol. 2019;56:561-7.

12. Kerr M, Barron E, Chadwick P, Evans T, Kong WM, Rayman G, et al. The cost of diabetic foot ulcer and amputations to the National Health Service in England. Diabet Med. 2019;36:995-1002.

13. Bus SA, van Netten JJ, Monteiro-Soares M, Lipsky BA, Schaper NC. Diabetic foot disease: "the times they are a changing". Diabetes Metab Res Rev. 2020;36:e3249.

14. European Association for the Study of the Liver (EASL), European Association for the Study of Diabetes (EASD), European Association for the Study of Obesity (EASO). Clinical practice guidelines for the management of non-alcoholic fatty liver disease. Obes Facts. 2016;9:65-90.

15. Bielby A. Understanding foot ulceration in patients with diabetes. Nurs Stand. 2006;20:57-67.

16. Pisanti P. Piano Strategico Nazionale sulla malattia diabetica. (Italian) G It Diabetol Metab. 2014;34:1-4.

17. Becchi MA. Il caregiver del paziente complesso ed il suo addestramento. Manuale di educazione terapeutica ad uso degli operatori sanitari e socio-assistenziali. Italian ed. Roma: Panorama della Sanità; 2011.

18. Bandyk DF. The diabetic foot: pathophysiology, evaluation, and treatment. Semin Vasc Surg. 2018;31:43-8.

19. van Acker K, Leger P, Hartemann A, Chawla A, Siddiqui MK. Burden of diabetic foot disorders, guidelines for management and disparities in implementation in Europe: a systematic literature review. Diabetes Metab Res Rev. 2014;30:635-45.

20. Ballestri S, Romagnoli D, Nascimbeni F, Francica G, Lonardo A. Role of ultrasound in the diagnosis and treatment of nonalcoholic fatty liver disease and its complications. Expert Rev Gastroenterol Hepatol. 2015;9:603-27.

21. Petta S, Valenti L, Bugianesi E, Targher G, Bellentani S, F Bonino; Special Interest Group on Personalised Hepatology of the Italian Association for the Study of the Liver (AISF), Special Interest Group on Personalised Hepatology of Italian Association for Study of Liver AISF. A "system medicine" approach to the study of nonalcoholic fatty liver disease. Dig Liv Dis. 2016;48:333-42.

22. Sayiner ZA, Can FI, Akarsu E. Patients' clinical charecteristics and predictors for diabetic foot amputation. Prim Care Diabetes. 2019;13:247-51.

23. Regensteiner JG, Golden S, Huebschmann AG, Barrett-Connor E, Chang AY, Chyun D,et al. Sex differences in the cardiovascular consequences of diabetes mellitus: a scientific statement from the american heart association. Circulation. 2015;132:2424-47.

24. Libby P, Ridker PM, Maseri A. Inflammation and atherosclerosis. Circulation. 2002;105:1135-43.

25. Rossaneis MA, Haddad MCLF, Mathias TAF, Marcon SS. Differences in foot self-care and lifestyle between men and women with diabetes mellitus. Rev Lat Am Enfermagem. 2016;24:e2761.

26. Pollak AW. PAD in women: the ischemic continuum. Curr Atheroscler Rep. 2015;17:513.

27. Sigvant B, Wiberg-Hedman K, Bergqvist D, Rolandsson O, Andersson B, Persson E, et al. A populationbased study of peripheral arterial disease prevalence with special focus on critical limb ischemia and sex difference. J Vasc Surg. 2007;45:1185-91.

28. Katsiki N, Giannoukas AD, Athyros VG, Mikhailidis DP. Lipid-lowering treatment in peripheral artery disease. Curr Opinion Pharmacol. 2018;39:19-26.

29. Mach F, Baigent C, Catapano AL, Koskinas KC, Casula M, Badimon L, et al. 2019 ESC/EAS guidelines for the management of dyslipidaemias: lipid modification to reduce cardiovascular risk. Eur Heart J. 2020;41:111-88. 
30. Meloni M, Izzo V, Giurato L, Lázaro-Martínez JL, Uccioli L. Prevalence, clinical aspects and outcomes in a large cohort of persons with diabetic foot disease: comparison between neuropathic and ischemic ulcers. J Clin Med. 2020;9:1780.

31. Aiello A, Anichini R, Brocco E, Caravaggi C, Chiavetta A, Cioni R, et al. Treatment of peripheral arterial disease in diabetes: a consensus of the Italian Societies of Diabetes (SID, AMD), Radiology (SIRM) and Vascular Endovascular Surgery (SICVE). Nutr Metab Cardiovasc Dis. 2014;24:355-69.

32. American Diabetes Association. Cardiovascular disease and risk management: standards of medical care in diabetes. Diabetes Care. 2019;42:S103-23.

33. Emdin CA, Rahimi K, Neal B, Callender T, Perkovic V, Patelet A, al. Blood pressure lowering in type 2 diabetes: a systematic review and meta-analysis. JAMA. 2015;313:603-15.

34. Xie X, Atkins E, Lv J, Bennett A, Neal B, Ninomiya T, et al. Effects of intensive blood pressure lowering on cardiovascular and renal outcomes: updated systematic review and meta-analysis. Lancet. 2016;387:435-43.

35. Cosentino F, Grant PJ, Aboyans V, Bailey CJ, Ceriello A, Delgado V, et al. 2019 ESC Guidelines on diabetes, pre-diabetes, and cardiovascular diseases developed in collaboration with the EASD. Eur Heart J. 2020;41:255-323.

36. Buse JB, Wexler DJ, Tsapas A, Rossing P, Mingrone G, Mathieu C, et al. 2019 Update to: management of hyperglycemia in type 2 diabetes, 2018. A consensus report by the American Diabetes Association (ADA) and the European Association for the Study of Diabetes (EASD). Diabetes Care.2020:43:487-93.

37. Callaghan BC, Little AA, Feldman EL, Hughes RAC. Enhanced glucose control for preventing and treating diabetic neuropathy. Cochrane Database Syst Rev. 2012;6:CD007543.

38. Gregersen S. Good glycaemic control can prevent diabetic peripheral neuropathy. Ugeskr Laeger. 2013;175:2022-5.

39. ORIGIN Trial Investigators; Gerstein HC, Bosch J, Dagenais GR, Díaz R, Jung H, et al. Basal insulin and cardiovascular and other outcomes in dysglycemia. N Engl J Med. 2012;367:319-28.

40. Marso SP, McGuire DK, Zinman B, Poulter NR, Emerson SS, Pieber TR, et al. Efficacy and safety of degludec versus glargine in type 2 diabetes. N Engl J Med. 2017;377:723-32.

41. Vatankhah N, Jahangiri Y, Landry GJ, Moneta GL, Azarbal AF. Effect of systemic insulin treatment on diabetic wound healing. Wound Repair Regen. 2017;25:288-91.

42. Beckman JA, Creager MA. Vascular complications of diabetes. Circ Res. 2016;118:1771-85.

43. Grebe A, Hoss F, Latz E. NLRP3 inflammasome and the IL-1 pathway in atherosclerosis. Circ Res. 2018;122:1722-40.

44. Garofolo L, Ferreira SRG, Miranda Júnior F. Association between peripheral arterial disease and C-reactive protein in the japanese-brazilian population. Rev Colégio Bras Cir. 2014;41:168-75.

45. Ridker PM, Danielson E, Fonseca FA, Genest J, Gotto AM Jr, Kastelein JJP, et al. Rosuvastatin to prevent vascular events in men and women with elevated C-reactive protein. N Engl J Med. 2008;359:2195-207.

46. Lavery LA, Ahn J, Ryan EC, Bhavan K, Oz OK, La Fontaine J, et al. What are the optimal cutoff values for ESR and CRP to diagnose osteomyelitis in patients with diabetes-related foot infections? Clin Orthop Relat Res. 2019;477:1594-602.

47. Hagstrom H, Nasr P, Ekstedt M, Hammar U, Stål P, Askling J, et al. Cardiovascular risk factors in nonalcoholic fatty liver disease. Liver Int. 2019;39:197-204.

48. Mantovani A, Petracca G, Beatrice G, Tilg H, Byrne CD, Targher G, et al. Non-alcoholic fatty liver disease and risk of incident diabetes mellitus: an updated meta-analysis of 501.022 adult individuals. Gut. 2020; [Epub ahead of print]. 
49. Lonardo A, Lugari S, Ballestri S, Nascimbeni F, Baldelli E, Maurantonio M, et al. A round trip from nonalcoholic fatty liver disease to diabetes: molecular targets to the rescue? Acta Diabetol. 2018;56:385-96.

50. Zou Y, Li X, Wang C, Wang J, Wang F, Ma L, et al. Association between non-alcoholic fatty liver disease and peripheral artery disease in patients with type 2 diabetes. Intern Med J. 2017;47:1147-53.

51. Italian Association for the Study of the Liver (AISF). AISF position paper on nonalcoholic fatty liver disease (NAFLD): updates and future directions. Dig Liver Dis. 2017;49:471-83.

52. Low Wang CC, Hess CN, Hiatt WR, Goldfine AB. Atherosclerotic cardiovascular disease and heart failure in type 2 diabetes - mechanism, management and clinical considerations. Circulation. 2016;133:2459-02.

53. Ridker PM, Hennekens CHBuring JE, Rifai N. C-reactive protein and other markers of inflammation in the prediction of cardiovascular events in women. N Engl J Med. 2000;342:836-43.

54. Maurantonio M, Ballestri S, Odoardi MS, Lonardo A, Loria P. Treatment of atherogenic liver based on the pathogenesis of nonalcoholic fatty liver disease: a novel approach to reduce cardiovascular risk? Archives Med Res. 2011;42:337-53. 